\title{
Altered expression of the Smad signalling pathway: implications for COPD pathogenesis
}

\author{
A. Zandvoort*, , D.S. Postma\#, M.R. Jonker*, J.A. Noordhoek\#, J.T.W.M. Vos*, \\ Y.M. van der Geld* and W. Timens*
}

ABSTRACT: Pulmonary emphysema, as a feature of chronic obstructive pulmonary disease (COPD), is characterised by destruction of alveolar tissue. The present authors previously demonstrated reduced decorin expression in the peribronchial area of COPD patients, reflecting an altered extracellular matrix (ECM) modulation. Decorin transcription is regulated by the transforming growth factor (TGF)- $\beta$-Smad pathway, the key intracellular signal route for initiation of ECM component gene transcription. Whether this pathway is aberrantly expressed in COPD is not known.

An immunohistochemical study was performed to compare protein expression of TGF- $\beta_{1}$ and TGF- $\beta$ receptors, Smad 2, 3, 4 and 7, and decorin in lung tissue of Global Initiative for Chronic Obstructive Lung Disease (GOLD) stages II and IV COPD patients and controls.

Epithelial expression of the inhibitory Smad 7 was significantly lower in patients with GOLD stages II and IV than in controls, with other Smad protein expressions being similar in the groups. The expression of TGF- $\beta_{1}$ and TGF- $\beta$ receptor type I was significantly lower in stage II patients. Decorin staining of the adventitia and alveolar walls was significantly reduced in COPD stage IV.

In conclusion, the transforming growth factor- $\beta-S m a d$ pathway is aberrantly expressed in chronic obstructive pulmonary disease patients, implying an abnormal tissue repair ultimately resulting in reduced decorin production. The results of the present study contribute to better understanding of the pathogenesis of emphysema and the airway fibrosis observed in chronic obstructive pulmonary disease patients.

KEYWORDS: Chronic obstructive pulmonary disease, emphysema, immunohistochemistry, Smad, transforming growth factor- $\beta_{1}$, tumour necrosis factor- $\alpha$

hronic obstructive pulmonary disease (COPD) is a chronic, often disabling respiratory disease associated with smoking. Approximately 15-20\% of smokers develop COPD and $\sim 95 \%$ of COPD patients have a positive smoking history [1-3]. COPD is characterised by airflow limitation that is slowly progressive and at best only partially reversible [3]. It encompasses chronic bronchitis, emphysema and small airways disease. Chronic bronchitis is defined by chronic clinical symptoms such as cough and sputum production. In addition, an extensive fibrotic process in the central airway walls can be observed. Emphysema is histopathologically characterised by loss of alveolar structure due to alveolar wall damage, which results in large airspaces in the parenchyma in combination with extensive inflammation [1, 3, 4]. Emphysema is often accompanied by small airways disease, characterised by a fibrotic process in the small airways, which also contributes to the airflow limitation $[1,5]$.

Smoking and its associated tissue damage give rise to an extensive inflammatory environment in the lungs of susceptible individuals. This results in the production of a large variety of cytokines involved in the pathological process of COPD. Transforming growth factor (TGF)- $\beta_{1}$ is one of these cytokines and induces a wide diversity of biological processes that regulate extracellular matrix (ECM) component production. Thus, TGF$\beta_{1}$ is important to ECM repair and modulation processes [2, 6-9]. The intracellular TGF- $\beta_{1^{-}}$ induced signal is mediated through the so-called Smad pathway $[6,10,11]$ (fig. 1).

The TGF- $\beta_{1}$ signal is received by TGF- $\beta$ receptor II, which in turn activates TGF- $\beta$ receptor I. This activated TGF- $\beta$ receptor complex results in

\section{AFFILIATIONS}

Depts of *Pathology and Laboratory Medicine, and

\#Pulmonology, University Medical Center Groningen, University of Groningen, Groningen, The Netherlands.

\section{CORRESPONDENCE}

W. Timens

University Medical Center Groningen University of Groningen

Dept of Pathology and Laboratory Medicine

Hanzeplein 1

$9713 \mathrm{GZ}$

Groningen

The Netherlands

Fax: 31503632510

E-mail: w.timens@path.umcg.nl

Received:

July 052005

Accepted after revision:

April 262006

SUPPORT STATEMENT

The present study was supported by a grant from the Dutch Asthma

Foundation (grant number 3.2.02.47). 


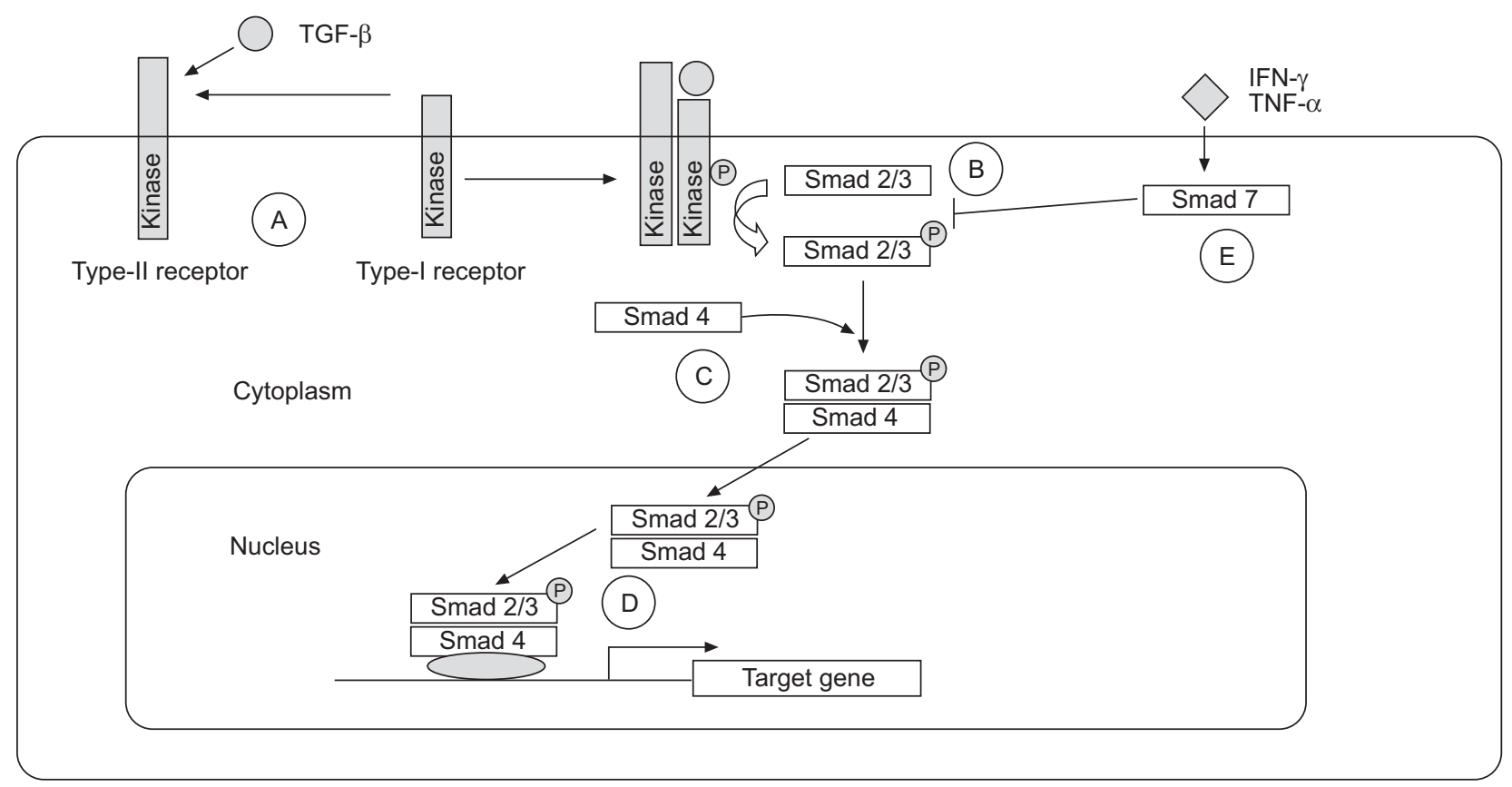

FIGURE 1. The transforming growth factor (TGF)- $\beta-$ Smad pathway. Binding of TGF- $\beta_{1}$ to its type-II receptor in concert with the type-I receptor (A) leads to the formation of a receptor complex and phosphorylation (P) of the type-l receptor. The type-l receptor subsequently phosphorylates Smad 2 or 3 (B), allowing this complex to associate with Smad 4 and move into the nucleus (C). In the nucleus, the Smad complex associates with a transcription factor and this complex binds to specific enhancers in target genes, (down-) regulating transcription (D). Tumour necrosis factor (TNF)- $\alpha$ and interferon (IFN)- $\gamma$ are able to interfere with the TGF- $\beta_{1}$ signalling, through the upregulation of the inhibitory Smad 7 protein $(E)$.

phosphorylation of the Smad 2-Smad 3 complex, which in turn can interact with the transporter Smad 4. This complex is able to enter the nucleus and initiate gene transcription. Smad 7 in turn can affect this pathway by inhibiting the phosphorylation of the Smad 2-Smad 3 complex. Smad 7 is activated by proinflammatory cytokines, such as tumour necrosis factor- $\alpha$ and interferon- $\gamma$ [11]. The TGF- $\beta-S m a d$ pathway regulates transcription of ECM proteins, such as decorin and biglycan, but also matrix metalloproteinases (MMP) and tissue inhibitors of MMP [6, 9]. In the past, it has been demonstrated that decorin and biglycan, two important proteoglycans of the ECM, show a diminished presence in lung tissue of COPD patients [12, 13]. In addition, isolated fibroblasts of stage IV COPD patients showed strongly reduced decorin production under the influence of TGF- $\beta$ stimulation [14]. Other ECM components, such as elastin and collagens, are also differentially expressed in lung tissue of COPD patients [15]. This led the current authors to hypothesise that the TGF- $\beta-S m a d$ pathway is altered in COPD patients and could serve as an explanation for the defective tissue repair observed in COPD [14].

The present study analysed several components of the TGF- $\beta-$ Smad pathway on protein level in lung tissue of patients with moderate (stage II Global Initiative for Chronic Obstructive Lung Disease (GOLD) criteria [16]) and very severe COPD (GOLD stage IV). Aberrant Smad pathway expression was associated with the expression of decorin in COPD lung tissue. Since smoking may directly affect protein expression, the patient groups were stratified according to smoking history.

\section{PATIENTS AND METHODS Subjects}

Lung tissue was obtained from 27 individuals. Classification of COPD severity was based on the 2003 GOLD criteria [16], using three criteria groups: 1) patients with moderate COPD (GOLD stage II, $n=11$ ); 2) patients with very severe COPD (GOLD stage IV, $n=8$ ); and 3) individuals with histologically normal lungs $(n=8)$. Chronic bronchitis and $\alpha_{1}$-antitrypsindeficient patients were excluded. No patient or control used inhaled corticosteroids. Emphysema is defined as histologically abnormal permanent enlargements of the airspaces distal to the terminal bronchioles, accompanied by destruction of their walls [17, 18]. Emphysema was assessed by routine histological examination of lung tissue, which was performed by an experienced pulmonary pathologist (W. Timens). The clinical characteristics of the groups are presented in table 1.

Tissue of GOLD stage II COPD patients (average forced expiratory volume in one second (FEV1) $68 \%$ of predicted) was derived from noninvolved lung tissue from patients undergoing resective surgery for pulmonary carcinoma. Tissue was always taken as far away as possible from the tumour, or from a noninvolved lobe. Histopathologically emphysematous lesions were present, however, of limited but varying severity. The moderate forms can be histopathologically demonstrated by the finding of isolated or free-lying segments of viable alveolar septal tissue or isolated cross sections of pulmonary vessels.

Tissue of GOLD stage IV COPD patients (average FEV1 21\% pred) was obtained from patients with COPD undergoing 
TABLE 1 Characteristics of the patient groups

\begin{tabular}{|c|c|c|c|}
\hline & Control & Stage II & Stage IV \\
\hline Subjects $n$ & 8 & 11 & 8 \\
\hline Age yrs & $63(36-78)$ & $68(44-81)$ & $54(44-61)$ \\
\hline Male/female & $4 / 4$ & $10 / 1$ & $1 / 7$ \\
\hline Smoking $(C / E x / N)$ & $3 / 3 / 2$ & $6 / 5 / 0$ & $0 / 8 / 0$ \\
\hline Pack-yrs smoking & $27(0-75)$ & $40(14-58)$ & $31(12-54)$ \\
\hline FEV $1 \%$ pred & $104(83-134)$ & $68(50-76)^{\#}$ & $21(13-29)^{\#}$ \\
\hline FEV $_{1 / F V C} \%$ & $74(70-81)$ & $53(37-68)^{\#}$ & $35(24-66)^{\#}$ \\
\hline Chronic bronchitis & No & No & No \\
\hline \multicolumn{4}{|c|}{$\begin{array}{l}\text { Data are presented as mean (range), unless otherwise stated. Stage II: Global } \\
\text { Initiative for Chronic Obstructive Lung Disease (GOLD) stage II chronic } \\
\text { obstructive pulmonary disease (COPD); Stage IV: GOLD stage IV COPD; C: } \\
\text { current smoker; Ex: ex-smoker, not smoking for } \geqslant 1 \mathrm{yr} \text {; N: never-smoker; FEV } 1 \text { : } \\
\text { forced expiratory volume in one second; } \% \text { pred: percentage of predicted } \\
\text { value; FVC: forced vital capacity. }{ }^{*} \text { : indicates a significant difference compared } \\
\text { with the control group. }\end{array}$} \\
\hline
\end{tabular}

surgery for lung transplantation or lung volume reduction. All individuals had to quit smoking for at least $1 \mathrm{yr}$ before surgery. The resected tissue showed both macroscopically and microscopically severe emphysematous lesions, often accompanied by bullae. Subpleural, fibrous areas were avoided.

Tissue from the control group (average FEV1 104\% pred) was derived from noninvolved lung tissue from patients undergoing resective surgery for pulmonary carcinoma. Patients had no airway obstruction and no chronic airway symptoms, such as cough and sputum production. Material was always taken from as far away as possible from the tumour, or from a noninvolved lobe. No histopathological lesions were present. Informed consent was given by all patients.

\section{Antibodies}

The following rabbit polyclonal antibodies were used: antiTGF- $\beta_{1}$, which detects latent as well as active TGF- $\beta_{1}(1: 100)$; anti-TGF- $\beta$ receptor type 2 (1:200); anti-Smad 4 (1:200); and anti-Smad 7 (1:100), all purchased from Santa Cruz Biotechnology, Inc. (Santa Cruz, CA, USA). Monoclonal antiSmad 2 (1:100) and rabbit polyclonal anti-TGF- $\beta$ receptor type
1 (1:100) were purchased from Cell Signaling Technologies (Beverly, MA, USA). Rabbit polyclonal anti-Smad 3 (1:200) was purchased from Zymed Laboratories Inc. (San Francisco, CA, USA). Mouse monoclonal anti-decorin (1:1000) was purchased from Seikagaku Corporation (Tokyo, Japan).

\section{Immunohistochemistry}

Immunohistochemistry was performed on $3-\mu \mathrm{m}$ formalinfixed, paraffin-embedded lung tissue using a two-step immunoperoxidase protocol. Sections were deparaffinised and citrate buffer and heating (8-min boiling in microwave oven) were used as an antigen-retrieval method. Endogenous peroxidase activity was blocked by incubation with $0.3 \%$ (volume/volume) $\mathrm{H}_{2} \mathrm{O}_{2}$ for $30 \mathrm{~min}$. Subsequently, sections were incubated with a primary antibody diluted in PBS supplemented with $1 \%$ (weight/volume) bovine serum albumin overnight at $4{ }^{\circ} \mathrm{C}$. Sections were incubated with a secondary antibody system (Envision; Dakopatts, Glostrup, Denmark) for $30 \mathrm{~min}$ at room temperature. After each incubation step, sections were rinsed in PBS for $5 \mathrm{~min}$. Peroxidase activity was demonstrated by application of $3,3^{\prime}$ diaminobenzidine (Sigma, St. Louis, MO, USA) containing $0.03 \% \mathrm{H}_{2} \mathrm{O}_{2}$ for $15 \mathrm{~min}$. Sections were counterstained with Mayers haematoxylin, dehydrated and mounted with mounting medium (Merck, Darmstadt, Germany). An irrelevant rabbit polyclonal antibody was used as a control and was always negative.

\section{Analysis and statistics}

Sections were scored semiquantitatively by two persons as follows: strongly positive staining $=3$; moderately positive $=2$; weakly positive $=1$; and negative $=0$. Statistical analysis was performed by a nonparametric Kruskal-Wallis test. A p-value of $<0.05$ was considered significant. A nonparametric MannWhitney U-test was used as a post hoc test to analyse the differences between controls and stage II, and between controls and stage IV groups.

\section{RESULTS}

\section{Patient characteristics}

Current smokers and ex-smokers were evenly distributed in the control and stage II groups, while the stage IV group consisted of only ex-smokers. No significant differences in age or pack-yrs smoking were found between subjects from the control group versus the two patient groups. The control group

\section{TABLE 2 Results from semiquantitative scoring of immunohistochemistry sections}

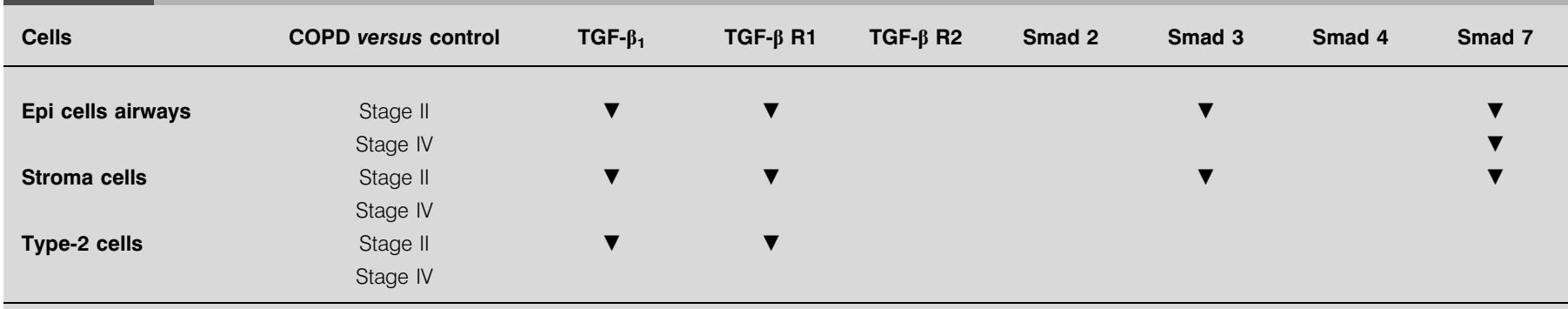

COPD: chronic obstructive pulmonary disease; TGF: transforming growth factor; epi: epithelial; Stage II: Global Initiative for Chronic Obstructive Lung Disease (GOLD) stage II COPD; Stage IV: GOLD stage IV COPD. $\mathbf{\nabla}$ : indicates a significantly lower expression in the stage II or stage IV group compared with the control group. No significant upregulations were observed. 

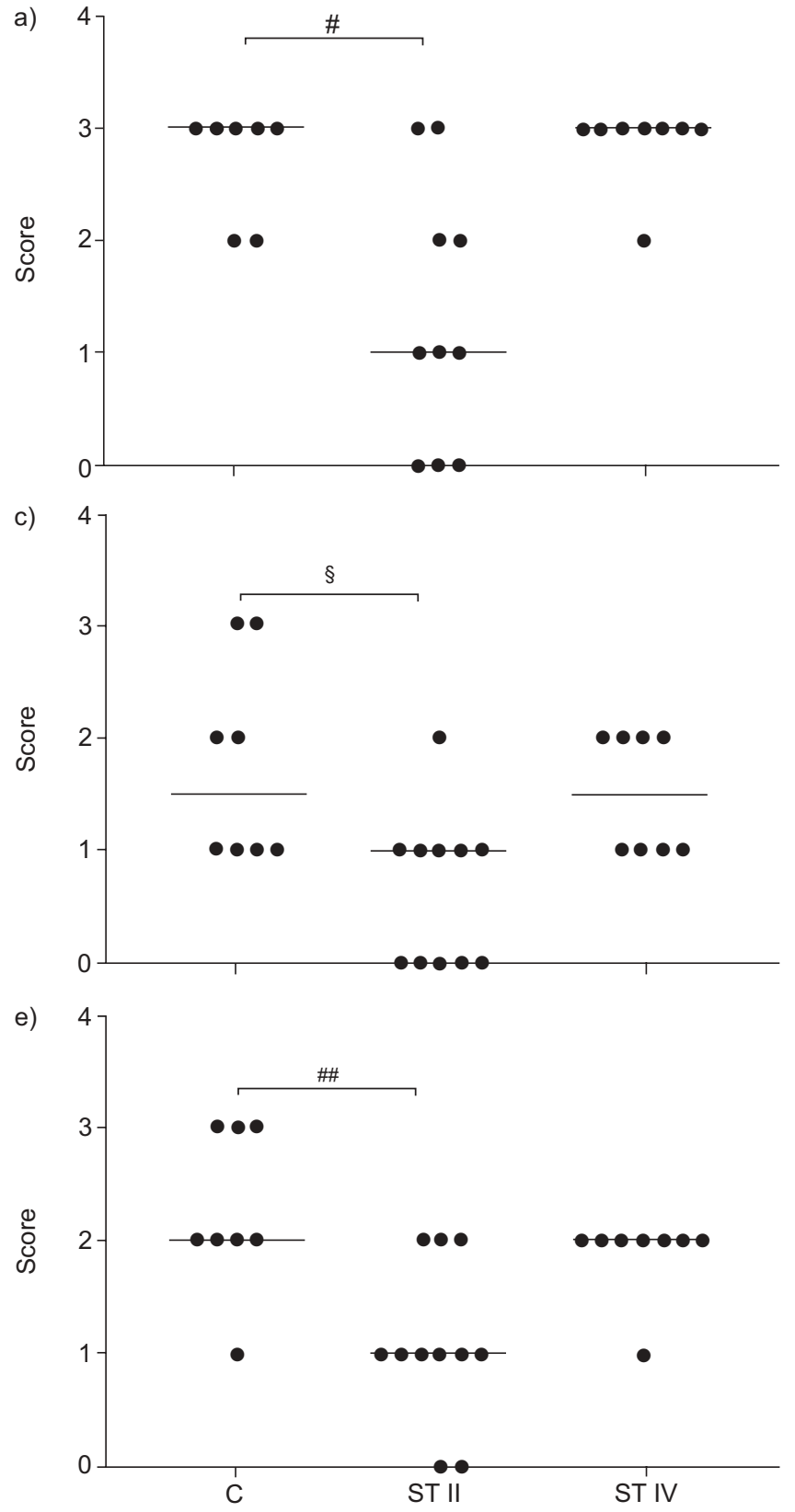

b)

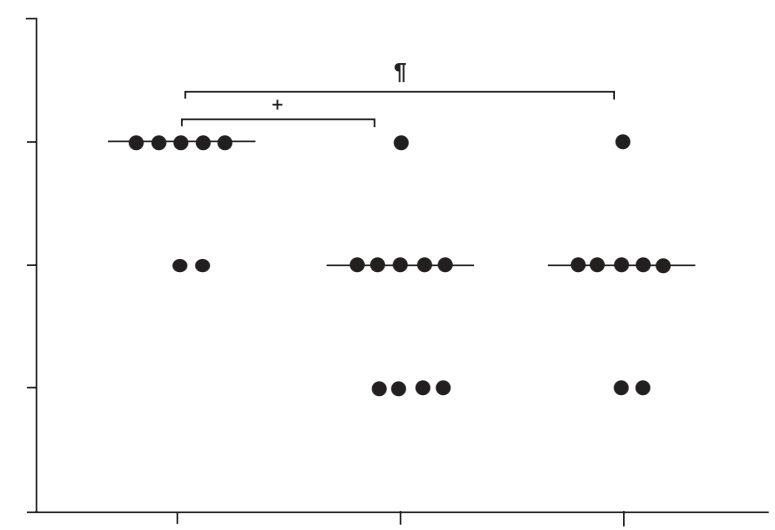

d)

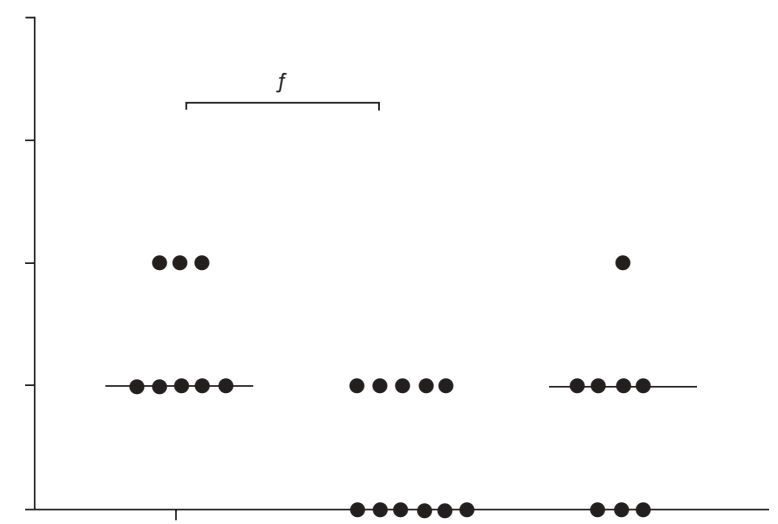

f)

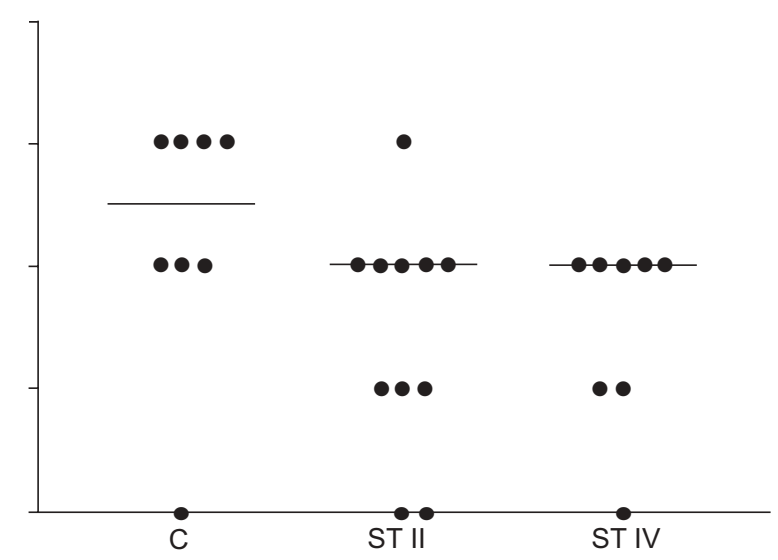

FIGURE 2. Semiquantitative scoring of transforming growth factor- $\beta_{1}$ expression in epithelial, stroma and type-2 pneumocytes (a, c and e, respectively) and Smad 7 expression in epithelial, stroma and type-2 pneumocytes (b, $d$ and f, respectively). C: control; ST II: Global Initiative for Chronic Obstructive Lung Disease (GOLD) stage II chronic obstructive pulmonary disease (COPD); ST IV: GOLD stage IV COPD. ${ }^{\#}: p=0.014 ;{ }^{\top}: p=0.019 ;{ }^{+}: p=0.008 ;{ }^{\varsigma}: p=0.010 ;{ }^{f}: p=0.033 ;{ }^{\# \#}: p=0.005$.

contained an equal number of males and females, the stage II and IV COPD groups contained predominantly males and females, respectively. FEV1 \% pred and FEV1/forced vital capacity (FVC) were significantly lower in the two patient groups than in the control group (table 1).

\section{TGF- $\beta$-Smad pathway histology}

Expression levels of TGF- $\beta_{1}$, TGF- $\beta$ receptor 1 and 2 , and Smad 2, 3, 4 and 7 were determined on airway epithelial cells, alveolar type 2 cells and stromal cells in the peribronchial area of small airways, the latter mostly resembling fibroblasts and myofibroblasts. Overall results are shown in table 2.
TGF- $\beta_{1}$ showed a significantly decreased expression in epithelial cells, stromal cells and type-2 alveolar pneumocytes in stage II COPD compared with controls (fig. 2). TGF- $\beta$ receptor 1 showed similarly decreased expressions in stage II (table 2). TGF- $\beta$ receptor 2 , Smad 2 and Smad 4 expression was not significantly different between the groups. Smad 3 expression was only significantly different in epithelial cells and stromal cells in stage II. Smad 7 showed a significantly decreased expression in epithelial cells of stage II, compared with controls (fig. 2). A significant decrease in Smad 7 expression in peribronchial stromal cells was also observed. However, in GOLD stage IV only a significant decrease in 

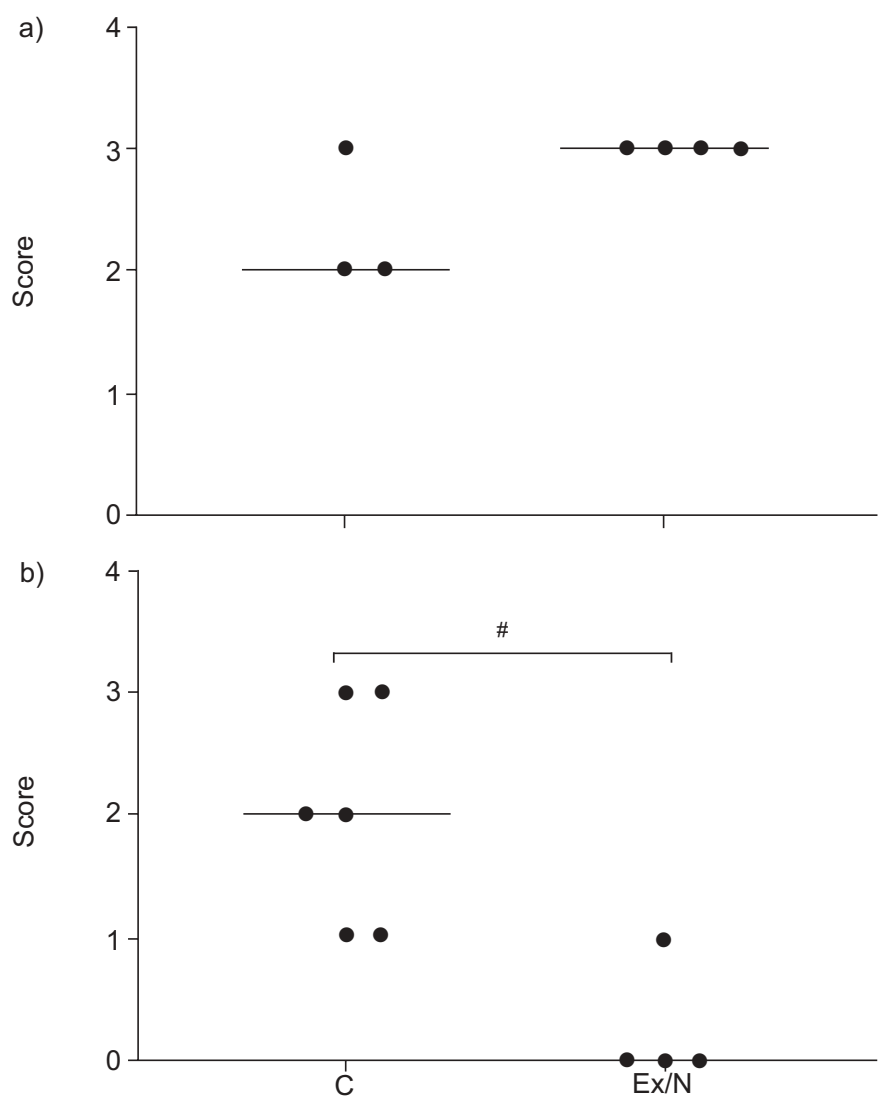

FIGURE 3. Association of smoking status with transforming growth factor- $\beta$ expression in a) controls and b) Global Initiative for Chronic Obstructive Lung Disease stage II chronic obstructive pulmonary disease patients. C: current smokers; Ex/N: ex-/never-smokers. ${ }^{\#}: p=0.016$.

epithelial Smad 7 expression was found in comparison with controls (fig. 2).

\section{Effects of smoking status on the TGF- $\beta$-Smad pathway}

The control and stage II groups consisted of smokers and exsmokers. For all antibodies used, the difference between smokers and ex-/never-smokers was analysed. The current authors found a significantly lower epithelial TGF- $\beta_{1}$ expression in stage II ex-/never-smokers than in current smokers (fig. 3). In controls, no significant differences were observed in TGF- $\beta$-Smad-related protein expression between smokers and ex-/never-smokers. In addition, no significant differences were found in the control group between ex- and never-smokers. Figure 4 shows representative histochemistry slides of the TGF- $\beta$ - and Smad 7-stained sections divided by smoking status. TGF- $\beta$ showed a decreased epithelial expression in exsmokers of stage II. Smad 7 showed a decreased expression in stage II as well as stage IV, but no relation with smoking status (fig. 4).

\section{Decorin expression}

To correlate the expression of the TGF- $\beta-S m a d$ pathway to ECM production, the current authors also stained decorin on the lung tissue samples of COPD patients. Intensity of staining was determined in the bronchial adventitia and alveolar septa. Decorin staining of the adventitia and alveolar walls was
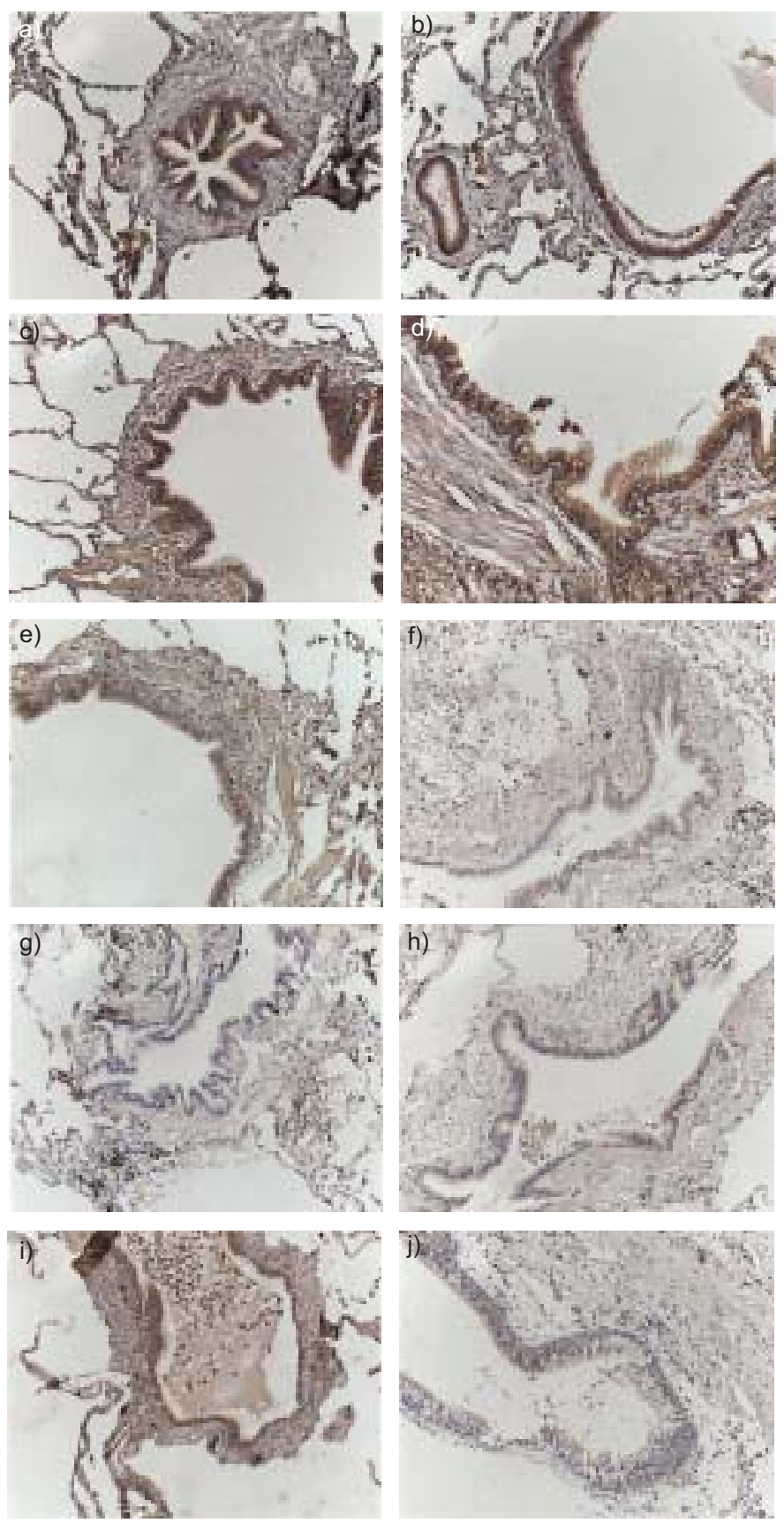

FIGURE 4. Immunohistochemistry of transforming growth factor- $\beta$ (a, c, e, g and i) and Smad 7 (b, d, f, h and j) expression in control current smokers (a, b), control ex-smokers (c, d), stage II chronic obstructive pulmonary disease (COPD) current smokers $(e, f)$, stage II COPD ex-smokers $(g, h)$ and stage IV COPD exsmokers (i, j).

significantly reduced in the COPD stage IV group (figs 5 and 6). No differences were observed between smokers and exsmokers (fig. 6).

\section{DISCUSSION}

COPD is a complex disease with alveolar destruction in the parenchyma on one hand, and a fibrotic process in the airway walls on the other. Fibroblasts are involved in ECM modulating reactions in the peribronchial area as well as the 

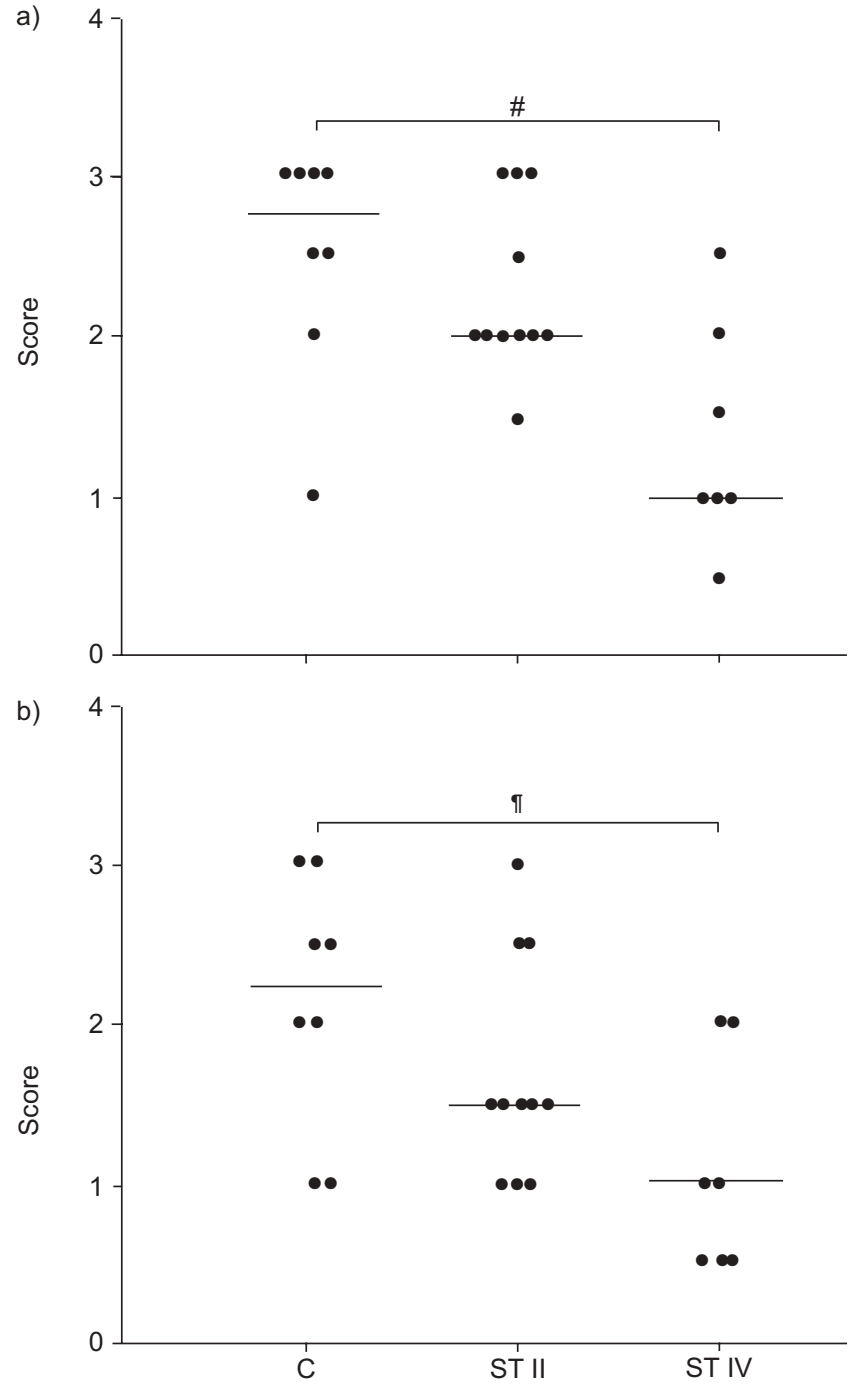

FIGURE 5. Semiquantitative scoring of decorin in a) airway adventitia and b) alveolar walls. C: control; ST II: Global Initiative for Chronic Obstructive Lung Disease (GOLD) stage II chronic obstructive pulmonary disease (COPD); ST IV: GOLD stage IV COPD. ${ }^{*}: p=0.0140 ;{ }^{\circ}: p=0.0205$.

parenchyma. Airway epithelial cells play an important role in modulation of the ECM in the airways while type-2 pneumocytes mainly modulate the ECM of the parenchymal and peribronchial area. TGF- $\beta_{1}$ is a potent inducer of ECM related components via the intracellular Smad signal transduction pathway. A disregulation of the TGF- $\beta$-Smad pathway possibly explains the defective ECM repair and maintenance in COPD patients. The present study shows downregulations in the expression of TGF- $\beta-$ Smad pathway proteins, which may have implications with respect to the pathogenesis of COPD.

In GOLD stage II patients, TGF- $\beta_{1}$ expression is significantly decreased in epithelial cells compared with controls. This contrasts to observations by DE BOER et al. [19], since they found a small but significant increase in TGF- $\beta_{1}$ expression in small airway epithelium of lung sections from COPD patients. In a study by TAKIZAWA et al. [20], mRNA and protein expression was also elevated in small airways epithelium. The discrepancies between the current study and that of TAKIZAWA et al. [20] can be explained by the observation that they applied no subdivision of COPD stage according to GOLD criteria. Furthermore, DE BOER et al. [19] included patients with chronic bronchitis, whereas TAKIZAWA et al. [20] did not specify this. Chronic bronchitis is defined by clinical symptoms and characterised by fibrosis and mucus hypersecretion in the airway walls and increased TGF- $\beta_{1}$ expression $[2,21]$. Thus, the inclusion of chronic bronchitis patients may explain the higher TGF- $\beta_{1}$ expression observed in the study by DE BOER et al. [19], and possibly also in the study of TAKIZAWA et al. [20] given the fact that the current authors specifically excluded chronic bronchitis patients in order to have a homogeneous population of COPD patients.

The TGF- $\beta_{1}$-induced Smad pathway has several important functions in cells, including: differentiation, induction of apoptosis and ECM component synthesis [22]. TGF- $\beta$ induces the production of TGF- $\beta_{1}$ via an autocrine loop, thereby amplifying the primary TGF- $\beta$ signal [23]. Increased presence of TGF- $\beta_{1}$ in the parenchyma may protect against emphysema as demonstrated in a mouse model where constitutive expression of TGF- $\beta_{1}$ prevented emphysema development [24]. TGF- $\beta_{1}$ inhibits MMP-12, an elastin-degrading MMP that is most probably regulated via the TGF- $\beta-$ Smad pathway. Low TGF- $\beta_{1}$ expression allows high MMP-12 expression resulting in elastin degradation and possibly emphysema [24, 25]. Furthermore, TGF- $\beta$ is a main effector of early tissue repair. Thus, the low TGF- $\beta$ and TGF- $\beta$ receptor 1 levels present in type- 2 cells in the current stage II COPD patients could point to an active tissue destructive process in the parenchyma due to the decreased inhibition of MMP-12. In addition, decreased activation of the TGF- $\beta$-Smad pathway will also result in a decreased production of ECM components, ultimately resulting in an active emphysema process.

The present authors found little differences in Smad 2, Smad 3 and Smad 4 protein expression. After phosphorylation of the Smad 2-Smad 3 complex, Smad 4 ligates to this complex. Subsequently, the resulting complex is transported to the nucleus in order to initiate gene transcription. The complex dissociates thereafter and cycles back to the TGF- $\beta$ receptors where the complex can be formed again $[10,26]$. This indicates that these particular Smad proteins can shuttle between the receptor complex and the nucleus. This could be an explanation as to why large differences in Smad 2, 3 or 4 expressions are not found on a protein level. This extends and supports the findings of SPRINGER et al. [27] who showed similar findings in bronchial biopsies of GOLD stage II COPD patients, yet with mRNA expression, i.e. no alterations in Smad 3, and 4 mRNA expression. SPRINGER et al. [27] did not detect Smad 2 mRNA expression in the tested bronchial biopsies, although they did detect Smad 2 mRNA in other tissues. In contrast, the current authors found Smad 2 protein expression, but without significant differences, between controls and COPD. This discrepancy can possibly be explained by the differences in the tissue used and the location analysed, e.g. bronchial biopsies versus lung tissue and bronchi versus small airways.

Smad 7 is the inhibitory Smad of the TGF- $\beta$-induced Smad pathway. The decreased bronchial epithelial Smad 7 

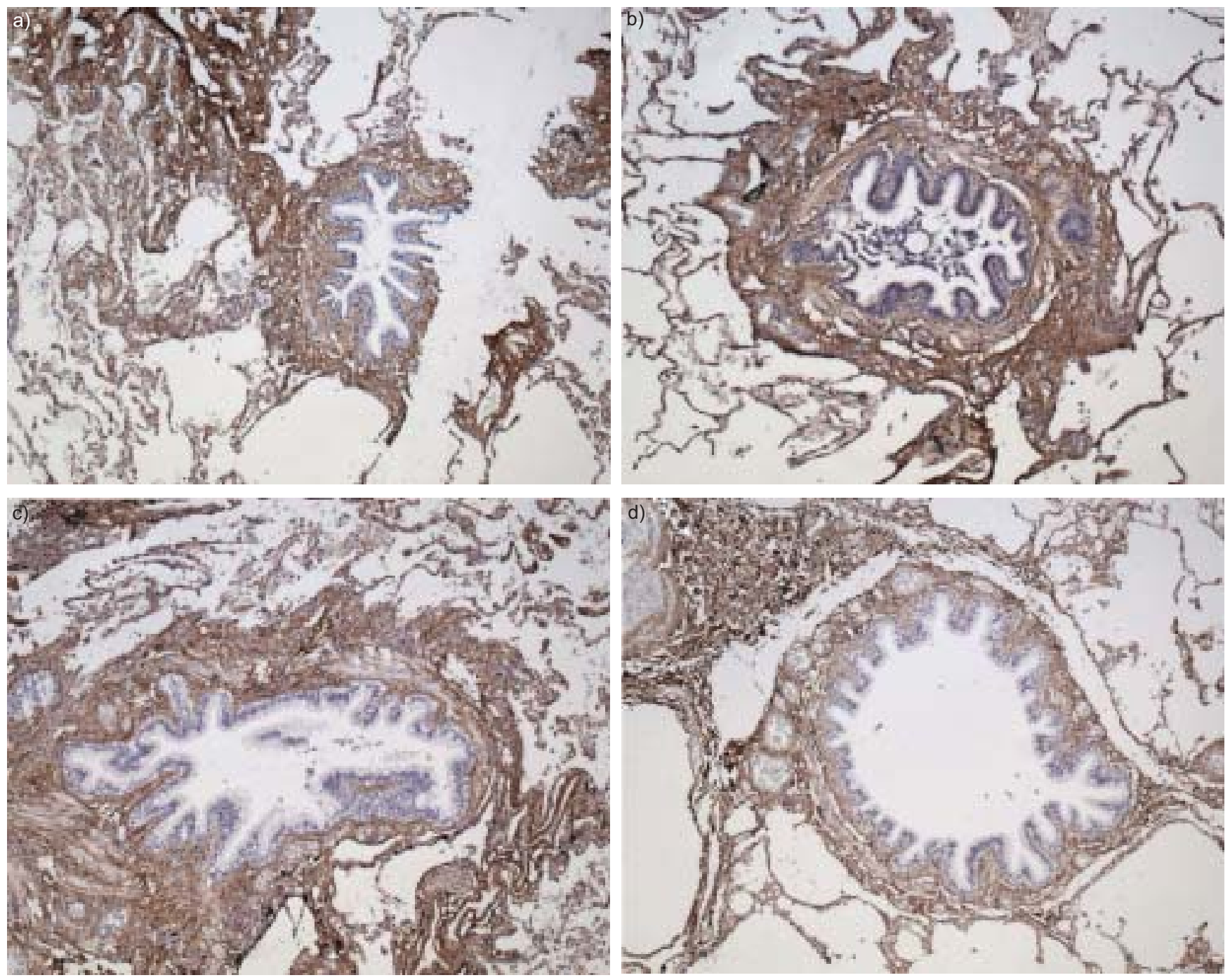

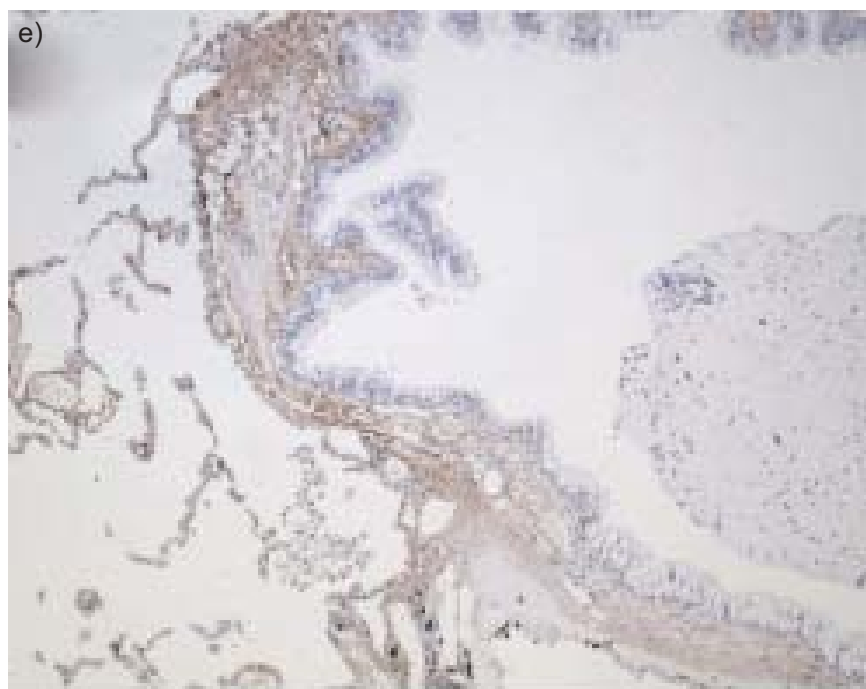

expression in patients with stage II, as well as stage IV, COPD indicates that there is possibly less inhibition of the TGF- $\beta$ Smad pathway. The functional outcome of Smad 7 inhibition is highly dependent on the presence of TGF- $\beta_{1}$ acting as Smad pathway activator. However, in stage II, the Smad pathway is
FIGURE 6. Immunohistochemistry of decorin expression in a) control current smoker, b) control ex-smoker, c) stage II chronic obstructive pulmonary disease (COPD) current smoker, d) stage II COPD ex-smoker, and e) stage IV COPD ex-smoker

less activated given the decreased TGF- $\beta_{1}$ and TGF- $\beta$ receptor I expression. This indicates that the balance between Smad 7 and TGF- $\beta_{1}$ is important in the functional outcome of emphysema. In stage IV, a decreased epithelial Smad 7 expression was found without significantly decreased TGF- $\beta_{1}$ expression. The 
differences between stage II and stage IV are possibly explained by the fact that in stage II patients there is still an ongoing damaging process to lung tissue while in stage IV this process is at an end stage, resulting in the necessity of lung transplantation.

The current results on Smad 7 are supported by the study of SPRINGER et al. [27] who demonstrated a reduced mRNA expression of Smad 7 in bronchial biopsies of COPD stage II patients in comparison with controls. Since they did not assess stage IV COPD patients, comparison was not possible. In asthma, NAKAO et al. [28] demonstrated that the expression of Smad 7 in bronchial epithelial cells is inversely correlated to basement membrane thickness and airway hyperresponsiveness. They found less Smad 7 expression in bronchial epithelial cells of asthmatics, suggesting an active remodelling process resulting in a thickened basement membrane. Although the previous studies have analysed bronchial epithelium and not small airways, the location where emphysema develops, results of these studies in combination with those of the present study results in small airways $(<2 \mathrm{~mm})$ suggest an important role for Smad 7 in regulation of airway remodelling. It is acknowledged that small airway remodelling contributes to airflow limitation in COPD [5]; hence, it is suggested that the balance between TGF- $\beta_{1}$ and Smad 7 also plays an important role in the pathogenesis of COPD.

The current authors have previously demonstrated a decreased expression of the proteoglycan decorin in the interstitial peribronchial area, which was most pronounced in stage IV COPD patients [13]. The present study confirms these findings and expands them by also finding reduced decorin expression in the alveolar walls of stage IV patients. The current authors have also shown that TGF- $\beta_{1}$ stimulation decreases decorin production of isolated pulmonary parenchymal fibroblasts of COPD patients [14]. Other studies have reported that decorin induction may be mediated by Smad 3 in combination with the vitamin D receptor [29]. The observed decreased decorin expression in stage IV COPD could, therefore, be the end-stage outcome of the decreased TGF- $\beta$-Smad pathway activity found in COPD patients with stage II, i.e. resulting in disease progression as reflected by GOLD stage III and IV. Although the Smad pathway seems to be relatively normally expressed in stage IV, apart from a decreased Smad 7 expression, the pathway is apparently incapable of repair of the matrix by adequately elevated decorin production.

The TGF- $\beta-$ Smad pathway is essential in the regulation of the transcription of genes involved in ECM remodelling and repair. This pathway appears to be actively reduced in stage II COPD patients, possibly resulting in the observed tissue destruction in the parenchyma and in a reduced decorin presence. The reduced Smad 7 expression may be an ultimate attempt to counterbalance the reduced presence of TGF- $\beta_{1}$, possibly resulting in airway fibrosis as a feature of small airways disease. In stage IV COPD patients, a reduced Smad 7 expression in epithelial cells was only observed, indicating a less inhibited TGF- $\beta-$ Smad pathway.

In conclusion, these results imply an active tissue remodelling or ultimate attempt for a repair process in chronic obstructive pulmonary disease patients. Thus, Smad 7 appears to be a common pathogenetic factor between stage II and stage IV chronic obstructive pulmonary disease and deserves further research.

\section{REFERENCES}

1 Barnes PJ, Shapiro SD, Pauwels RA. Chronic obstructive pulmonary disease: molecular and cellular mechanisms. Eur Respir J 2003; 22: 672-688.

2 Hogg JC. Pathophysiology of airflow limitation in chronic obstructive pulmonary disease. Lancet 2004; 364: 709-721.

3 Barnes PJ. New concepts in chronic obstructive pulmonary disease. Annu Rev Med 2003; 54: 113-129.

4 Di Stefano A, Caramori G, Ricciardolo FL, Capelli A, Adcock IM, Donner CF. Cellular and molecular mechanisms in chronic obstructive pulmonary disease: an overview. Clin Exp Allergy 2004; 34: 1156-1167.

5 Hogg JC, Chu F, Utokaparch S, et al. The nature of smallairway obstruction in chronic obstructive pulmonary disease. N Engl J Med 2004; 350: 2645-2653.

6 Schiller M, Javelaud D, Mauviel A. TGF-beta-induced SMAD signaling and gene regulation: consequences for extracellular matrix remodeling and wound healing. $J$ Dermatol Sci 2004; 35: 83-92.

7 Verrecchia F, Mauviel A. Transforming growth factor-beta signaling through the Smad pathway: role in extracellular matrix gene expression and regulation. J Invest Dermatol 2002; 118: 211-215.

8 Roberts AB, McCune BK, Sporn MB. TGF-beta: regulation of extracellular matrix. Kidney Int 1992; 41: 557-559.

9 Yamane $\mathrm{K}$, Ihn $\mathrm{H}$, Asano $\mathrm{Y}$, Jinnin M, Tamaki K. Antagonistic effects of TNF-alpha on TGF-beta signaling through down-regulation of TGF-beta receptor type II in human dermal fibroblasts. J Immunol 2003; 171: 3855-3862.

10 Ten Dijke P, Hill CS. New insights into TGF-beta-Smad signalling. Trends Biochem Sci 2004; 29: 265-273.

11 Itoh S, Itoh F, Goumans MJ, Ten Dijke P. Signaling of transforming growth factor-beta family members through Smad proteins. Eur J Biochem 2000; 267: 6954-6967.

12 van der Geld YM, van Straaten JF, Postma DS, Timens W. Role of proteoglycans in the development and pathogenesis of emphysema. In: Garg HG, Roughley PJ, Hales CA, eds. Proteoglycans in Lung Disease. New York, Marcel Dekker Inc., 2002; pp. 241-267.

13 van Straaten JF, Coers W, Noordhoek JA, et al. Proteoglycan changes in the extracellular matrix of lung tissue from patients with pulmonary emphysema. Mod Pathol 1999; 12: 697-705.

14 Noordhoek JA, Postma DS, Chong LL, et al. Different modulation of decorin production by lung fibroblasts from patients with mild and severe emphysema. J COPD 2005; 2 : 17-25.

15 Ohnishi K, Takagi M, Kurokawa Y, Satomi S, Konttinen YT. Matrix metalloproteinase-mediated extracellular matrix protein degradation in human pulmonary emphysema. Lab Invest 1998; 78: 1077-1087.

16 National Institute of Health, National Heart Lung and Blood Institute (NHLBI). Global strategy for the diagnosis, management, and prevention of chronic obstructive disease. Based on 1998 NHLBI/WHO workshop, April 2001 (updated 2003). 
17 Turato G, Zuin R, Saetta M. Pathogenesis and pathology of COPD. Respiration 2001; 68: 117-128.

18 Pauwels RA, Buist AS, Calverley PM, Jenkins CR, Hurd SS. Global strategy for the diagnosis, management, and prevention of chronic obstructive pulmonary disease. NHLBI/WHO Global Initiative for Chronic Obstructive Lung Disease (GOLD) Workshop summary. Am J Respir Crit Care Med 2001; 163: 1256-1276.

19 de Boer WI, van Schadewijk A, Sont JK, et al. Transforming growth factor beta1 and recruitment of macrophages and mast cells in airways in chronic obstructive pulmonary disease. Am J Respir Crit Care Med 1998; 158: 1951-1957.

20 Takizawa H, Tanaka M, Takami $\mathrm{K}$, et al. Increased expression of transforming growth factor-beta1 in small airway epithelium from tobacco smokers and patients with chronic obstructive pulmonary disease (COPD). Am J Respir Crit Care Med 2001; 163: 1476-1483.

21 Vignola AM, Chanez P, Chiappara G, et al. Transforming growth factor-beta expression in mucosal biopsies in asthma and chronic bronchitis. Am J Respir Crit Care Med 1997; 156: 591-599.

22 Ten Dijke P, Goumans MJ, Itoh F, Itoh S. Regulation of cell proliferation by Smad proteins. J Cell Physiol 2002; 191: 1-16.

23 Cutroneo KR, Phan SH. TGF-beta1-induced Smad 3 binding to the Smad 7 gene: knockout of Smad 7 gene transcription by sense phosphorothioate oligos, autoregulation, and effect on TGF-beta1 secretion: bleomycin acts through TGF-beta1. I Cell Biochem 2003; 89: 474-483.

24 Morris DG, Huang X, Kaminski N, et al. Loss of integrin alpha(v)beta6-mediated TGF-beta activation causes Mmp12-dependent emphysema. Nature 2003; 422: 169-173.

$25 \mathrm{Wu} \mathrm{L}$, Chau J, Young RP, et al. Transforming growth factor-beta1 genotype and susceptibility to chronic obstructive pulmonary disease. Thorax 2004; 59: 126-129.

26 Moustakas A, Souchelnytskyi S, Heldin CH. Smad regulation in TGF-beta signal transduction. J Cell Sci 2001; 114: 4359-4369.

27 Springer J, Scholz FR, Peiser C, Groneberg DA, Fischer A. SMAD-signaling in chronic obstructive pulmonary disease: transcriptional down-regulation of inhibitory SMAD 6 and 7 by cigarette smoke. Biol Chem 2004; 385: 649-653.

28 Nakao A, Sagara H, Setoguchi Y, et al. Expression of Smad7 in bronchial epithelial cells is inversely correlated to basement membrane thickness and airway hyperresponsiveness in patients with asthma. J Allergy Clin Immunol 2002; 110: 873-878.

29 Demoor-Fossard M, Galera P, Santra M, Iozzo RV, Pujol JP, Redini F. A composite element binding the vitamin D receptor and the retinoic $X$ receptor alpha mediates the transforming growth factor-beta inhibition of decorin gene expression in articular chondrocytes. J Biol Chem 2001; 276: 36983-36992. 